\title{
ANALISIS FAKTOR YANG BERHUBUNGAN DENGAN KINERJA BIDAN DESA DALAM PELAYANAN KESEHATAN IBU HAMIL DI KABUPATEN GOWA
}

\author{
The Analysis Of Factors Associated With Village Village Performance In Pregnant \\ Women's Health Services In Gowa District
}

\author{
Megawati \\ Akademi Keperawatan Lapatau, Kabupaten Bone, Indonesia \\ Email: meghaphutri@gmail.com
}

\begin{abstract}
ABSTRAK
Kinerja seseorang terkait erat dengan proses kerja dan faktor yang mempengaruhinya. Faktor yang mempengaruhi kinerja meliputi faktor individu dan factor organisasi. Untuk kinerja bidan maka faktor yang paling berpengaruh dan merupakan faktor kunci untuk mencapai hasil kerja yang baik harus memiliki kemampuan dan keterampilan yang baik, adanya kepuasaan kerja yang memadai, adanya motivasi yang kuat yang merupakan pendorong adanya imbalan/kompensasi yang memadai bagi bidan itu sendiri.

Penelitian ini bertujuan untuk menganalisis faktor yang berhubungan kemampuan, pengalaman, imbalan dengan kinerja bidan di Kabupaten Gowa.

Penelitian ini dilakukan dengan menggunakan Study Cross Sectional dengan pendekatan kuantitatif. Jenis data meliputi data primer dan data sekunder. Data primer meliputi data tentang kemampuan, pengalaman,dan imbalan dalam memberikan pelayanan KIA sedangkan data sekunder adalah data yang terkait dengan informasi perihal Bidan baik itu internal maupun eksternal.

Hasil penelitian menunjukkan bahwa Ada hubungan yang signifikan antara kemampuan dengan kinerja bidan desa di Kabupaten Gowa. Ada hubungan yang signifikan antara pengalaman dengan kinerja bidan desa di Kabupaten Gowa. Ada hubungan antara Imbalan dengan kinerja bidan desa di Kabupaten Gowa. Pengalaman yang paling berhubungan dengan kinerja bidan desa di Kabupaten Gowa.
\end{abstract}

Kata Kunci : Kemampuan, Pengalaman, Imbalan, kinerja

\section{ABSTRACT}

A person's performance is closely related to the work process and the factors that influence it. Factors that affect performance include individual factors and organizational factors. For the performance of the midwife, the most influential factor and a key factor in achieving good work must have good skills and skills, adequate job satisfaction, a strong motivation which is a driver of compensation / compensation that is adequate for the midwife itself.

This study aims to analyze the factors related to ability, experience, reward with the performance of midwives in Gowa District.

This research was conducted using Cross Sectional Study with a quantitative approach. Data types include primary data and secondary data. Primary data includes data about ability, experience, and rewards in providing $\mathrm{MCH}$ services while secondary data is data related to information about midwives both internally and externally.

The results showed that there was a significant relationship between ability and performance of village midwives in Gowa District. There is a significant relationship between experience with the performance of village midwives in Gowa District. There is a relationship between reward and performance of village midwives in Gowa District. The experience most related to the performance of village midwives in Gowa District.

Keywords: Ability, Experience, Rewards, performance

\section{PENDAHULUAN}

Saat ini di dunia Angka Kematian Ibu (AKI) saat melahirkan dan Angka Kematian Bayi khususnya bayi baru lahir masih tinggi. Menurut Survei Demografi Kesehatan
Indonesia (SDKI) Tahun 2002 Angka Kematian Ibu (AKI) di Indonesia sebesar 307/100.000 kelahiran hidup (KH) sedangkan hasil SDKI pada tahun 2007 AKI 228/100.000 KH. Dari pernyataan diatas 
terdapat penurunan angka kejadian,namun angka tersebut masih jauh Millenium Development Goals (MDGs) yang sudah harus dicapai pada tahun 2015 yaitu AKI 102/100.000 KH dan hasil SDKI 2007 mengetimasikan AKB sebesar 34/1000 kelahiran hidup (Profil Kesehatan Iindonesia,2012).

Di Sulawesi Selatan, berdasarkan hasil surkesnas 2012-2013 AKB di Sulawesi selatan sebesar 47/1000 KH. Di Kabupaten Gowa angka kematian bayi selama kurun waktu tahun 2009 sampai dengan tahun 2012 memperlihatkan penurunan yaitu 9,44/1000 KH menjadi 3,07/1000 KH pada tahun 2011. Namun AKB di kabupaten gowa mengalami peningkatan yaitu 4,3/ $1000 \mathrm{KH}$ pada tahun 2012 dan mengalami penurunan lagi yaitu 4,17 pada tahun 2013 (Profil Kesehatan Kabupaten Gowa,2013).

Angka Kematian Ibu dan Anak di Puskesmas Tinggimoncong Kabupaten Gowa pada tahun 2014 yakni 1 orang ibu dan 9 orang bayi, sementara di puskesmas parigi pada tahun 2014 tidak ada yang meninggal baik Ibu dan Bayi. Meski pada tahun 2013 dan 2014 di puskesmas parigi meninggal 1 orang bayi per tahun. Kemudian di puskesmas manuju meninggal 2 orang ibu dan 5 bayi pada tahun 2013. Dan di puskesmas parangloe pada tahun 2014 meninggal 1 orang ibu dan 1 orang bayi.

Beberapa kasus di lapangan menunjukkan bahwa secara umum penyebab utama kematian maternal adalah keterlambatan mencari, mencapai dan mendapatkan pelayanan kesehatan yang dibutuhkan dalam mengatasi komplikasi yang terjadi karena berbagai sebab. Pengetahuan yang kurang, jarak yang sulit di capai, bidan tidak berada di tempat merupakan penyebab pelayanan kesehatan tidak diperoleh ketika dibutuhkan. Disamping itu pula, pelayanan bidan masih kurang bermutu pada tujuh hari pasca persalinan. Bidan yang semestinya memberikan pelayanan dan konseling yang bermutu pada kunjungan rumah setelah tujuh hari pasca persalinan terkadang tidak melaksanakannya.

Dalam aspek pelayanan kesehatan salah satu penyebab tingginya Angka Kematian Ibu adalah karena Pelayanan Anternatal Care dan pertolongan persalinan oleh tenaga professional yang belum mampu terjangkau seluruh lapisan masyarakat. Keadaan ini menyebabkan masih banyak ibu tidak memeriksakan kehamilan dan banyak ibu tidak mendapatkan pelayanan ANC yang sesuai standar. Penempatan Bidan diharapkan mampu memberikan kontribusi terhadap penurunan angka kematina ibu dan bayi serta berperan untuk meningkatkan persepsi peran masyarakat berperilaku hidup sehat dan bersih. Kegiatan Bidan pada umumnya maliputi kegiatan yang berkaitan dengan palayanan KIA termasuk Keluarga Berencana, pengelolaan program KIA dan pembinaan peran serta masyarakat dalam bidang KIA (Depkes RI, 2012).

Kinerja seseorang terkait erat dengan proses kerja dan faktor yang mempengaruhinya. Faktor yang mempengaruhi kinerja meliputi Faktor individu yang terdiri atas kemapuan, persepsi peran, kemauan, keterampilan, latar belakang keluarga, pengalaman, tingkat sosial dan demografi (umur, asal, dan jenis kelamin), faktor organisasi yang terdiri dari; struktur organisasi, Daerah pekerjaan, kepemimpinan dan struktur imbalan/kompensasi serta faktor psikologis yang meliputi; persepsi, sikap, kepribadian, belajar, motivasi, dan kepuasaan kerja. Untuk kinerja Bidan maka faktor yang paling berpengaruh dan merupakan faktor kunci untuk mencapai hasil kerja yang baik harus memiliki kemampuan dan keterampilan yang baik, adanya kepuasaan kerja yang memadai, adanya motivasi yang kuat yang merupakan pendorong adanya imbalan/kompensasi yang memadai bagi bidan itu sendiri.

\section{METODE PENELITIAN}

Penelitian ini dilakukan dengan menggunakan Study cross sectional dengan pendekatan kuantitatif.Jenis data meliputi data primer dan data sekunder. Data primer meliputi data tentang kemampuan, pengalaman, dan imbalan Bidan dalam memberikan pelayanan KIA sedangkan data sekunder adalah data yang terkait dengan informasi perihal Bidan baik itu internal maupun eksternal.

Penelitian ini telah dilaksanakan pada bulan Desember 2015- Januari 2106 di Kabupaten Gowa Provinsi Sulawesi Selatan.

Populasi penelitian adalah keseluruhan subyek penelitian yaitu semua Bidan yang bekerja di Kabupaten Gowa. Sampel 
penelitian adalah bidan yang bekerja di Kabupaten Gowa dengan kriteria telah bekerja lebih dari 1 tahun disalah satu lokasi daerah binaan dan diambil perwakilan dari setiap Kecamatan.

Dalam pelaksanaan penelitian ini, data yang dikumpulkan akan diperoleh melalui metode berikut ini :

\section{a. Kuesioner}

Data primer mengenai

Kemampuan, Pengalan, Imbalan dalam memberikan pelayanan KIA akan dipeoleh melalui penyebaran kuesioner kepada seluruh Bidan.

\section{b. Wawancara}

Wawancara langsung dengan Bidan mampu menguak sejumlah temuan yang tidak dapat terjangkau oleh kuesioner. Wawancara juga dilakukan kepada pihak terkait lainnya seperti kepala puskesmas diwilayah Bidan bertugas serta petugas kesehatan terkait lainnya.

\section{c. Observasi}

metode lain dalam pengumpulan data adalah dengan melakukan pengamatan atau observasi terhadap kinerja Bidan yaitu pengamatan secara langsung dengan melakukan kunjungan lapangan.

\section{d. Dokumentasi}

Data seperti ini bisa saja beruapa table maupun angka yang diambil dari berbagai sumber, buku, surat kabar, majalah, artikel di internet atau referensi penelitian sejenis yang telah dilakukan sebelumnya oleh pihak lain dengan tujuan untuk membandingkan hasil penelitian sebelumnya dengan penelitian ini.

\section{HASIL PENELITIAN}

Distribusi Kemampuan, Pengalaman, Imbalan, Peralatan, dan Kinerja Bidan Desa

Tabel 1. Distribusi Kemampuan Terhadap Kinerja Bidan Di Kabupaten Gowa Tahun 2016.

\begin{tabular}{ccc}
\hline Kemampuan & $\begin{array}{c}\text { Jumlah } \\
\text { bidan }\end{array}$ & Persentase \\
\hline Kurang & 18 & 41,9 \\
\hline Baik & 25 & 58,1 \\
\hline Total & 43 & 100 \\
\hline
\end{tabular}

Sumber : Data Primer, 2016

Tabel 1. menunjukkan bahwa kemampuan bidan kategori kurang sebanyak
18 (41,9 \%) dan Kemampuan bidan baik sebesar $25(58,1 \%)$

Tabel 2. Distribusi Pengalaman Terhadap Kinerja Bidan Di Kabupaten Gowa Tahun 2016.

\begin{tabular}{ccc}
\hline Pengalaman & $\begin{array}{c}\text { Jumlah } \\
\text { bidan }\end{array}$ & Persentase \\
\hline Sedikit & 14 & 32,6 \\
\hline Banyak & 29 & 67,4 \\
\hline Total & 43 & 100 \\
\hline
\end{tabular}

Sumber : Data Primer, 2016

Tabel 2 menunjukkan bahwa responden yang mengalami pengalaman sedikit sebanyak 14 $(32,6 \%)$, sedangkan yang mempunyai pengalaman banyak sebanyak $29(67,4 \%)$. Pengalaman responden yang memiliki pengalaman banyak dalam pertolongan persalinan lebih besar dibandingkan dengan responden yang mempunyai pengalaman sedikit.

Tabel 3. Distribusi Imbalan Terhadap Kinerja Bidan Di Kabupaten Gowa Tahun 2016.

\begin{tabular}{ccc}
\hline Imbalan & $\begin{array}{c}\text { Jumlah } \\
\text { bidan }\end{array}$ & Persentase \\
\hline Kurang & 12 & 27,9 \\
\hline Lebih & 31 & 72,1 \\
\hline Total & 43 & 100 \\
\hline
\end{tabular}

Sumber : Data Primer, 2016

Tabel 3 Menunjukkan bahwa lebih besar responden menyatakan kurang 12 orang $(27,9$ $\%$ ), dan imbalan lebih sebanyak 31 orang $(72,1 \%)$

Tabel 9. Distribusi Kinerja Bidan Di Kabupaten Gowa Tahun 2016.

\begin{tabular}{|c|c|c|}
\hline $\begin{array}{c}\text { Kinerja } \\
\text { Bidan } \\
\text { Desa }\end{array}$ & $\begin{array}{c}\text { Jumlah } \\
\text { bidan }\end{array}$ & Persentase \\
\hline Kurang & 16 & 37,2 \\
\hline Baik & 27 & 62,8 \\
\hline Total & 43 & 100 \\
\hline
\end{tabular}

Tabel 3 Menunjukkan responden yang memiliki kinerja kurang sebanyak 16 orang $(37,2 \%)$ dan responden yang memiliki kinerja baik sebanyak 27 orang $(62,8 \%)$ 


\section{Analisis Bivariat}

Berikut ini akan dibahas hubungan kinerja bidan desa dengan kemampuan, pengalaman, dan imbalan dalam pertolongan persalinan yang akan dibahas pada tabel berikut ini :

a. Hubungan Kemampuan Dengan Kinerja Bidan

Tabel 4. Distribusi Kinerja Bidan Desa Menurut Kemampuan di Kabupaten Gowa Tahun 2016

\begin{tabular}{|c|c|c|c|c|c|c|c|}
\hline \multirow{3}{*}{ Kemampuan } & \multicolumn{4}{|c|}{ Kinerja Bidan } & \multirow{2}{*}{\multicolumn{2}{|c|}{ Total }} & \multirow{3}{*}{$\begin{array}{c}\text { Nilai P } \\
\text { (Chi square) }\end{array}$} \\
\hline & \multicolumn{2}{|c|}{ Kurang } & \multicolumn{2}{|c|}{ Baik } & & & \\
\hline & $\mathrm{N}$ & $\%$ & $\mathrm{n}$ & $\%$ & $\mathrm{~N}$ & $\%$ & \\
\hline Kurang & 7 & 38,9 & 11 & 61,1 & 18 & 100 & \\
\hline Baik & 9 & 36,0 & 16 & 64,0 & 25 & 100 & 0,047 \\
\hline Total & 16 & 37,2 & 27 & 62,8 & 43 & 100 & \\
\hline
\end{tabular}

Sumber : Data Primer, 2016

Responden yang memiliki kemampuan kurang kinerja kurang sebanyak 7 orang (38,9 $\%)$, kemampuan kurang kinerja baik sebanyak 11 orang $(61,1 \%)$. Responden yang memiliki kemampuan baik kinerja kurang sebanyak 9 orang $(36,0 \%)$, kemampuan baik kinerja baik 16 orang $(64,0 \%)$

Dari hasil uji chi square didapatkan hasil bahwa nilai p sebesar 0,047 . Hal ini berarti bahwa nilai $\mathrm{p}<$ dari 0,05 sehingga kemampuan berhubungan dengan kinerja bidan pada Kabupaten Gowa.

b. Hubungan Pengalaman Dengan Kinerja Bidan

Tabel 5. Distribusi Kinerja Bidan Desa Menurut Pengalaman di Kabupaten Gowa Tahun 2016

\begin{tabular}{|c|c|c|c|c|c|c|c|}
\hline \multirow{3}{*}{ Pengalaman } & \multicolumn{4}{|c|}{ Kinerja Bidan } & \multirow{2}{*}{\multicolumn{2}{|c|}{ Total }} & \multirow{3}{*}{$\begin{array}{c}\text { Nilai P } \\
\text { (Chi square) }\end{array}$} \\
\hline & \multicolumn{2}{|c|}{ Kurang } & \multicolumn{2}{|c|}{ Baik } & & & \\
\hline & $\mathrm{N}$ & $\%$ & $\mathrm{n}$ & $\%$ & $\mathrm{n}$ & $\%$ & \\
\hline Sedikit & 5 & 35,7 & 9 & 64,3 & 14 & 100 & \\
\hline Banyak & 11 & 37,9 & 18 & 62,1 & 29 & 100 & 0,004 \\
\hline Total & 16 & 37,2 & 27 & 62,8 & 43 & 100 & \\
\hline
\end{tabular}

Sumber : Data Primer, 2016

Tabel 5. Menunjukkan bahwa responden dengan pengalaman sedikit dan kinerja kurang sebanyak 5 (35,7\%), sedangkan kinerja baik sebanyak $9(64,3 \%)$. Responden yang mempunyai pengalaman banyak dengan kinerja kurang sebanyak $11(37,9 \%)$ sedangkan kinerja baik sebanyak $18(62,1 \%)$

Dari hasil uji chi square didapatkan hasil bahwa nilai p sebesar 0,004. Hal ini berarti bahwa nilai $\mathrm{p}<$ dari 0,05 sehingga pengalaman berhubungan dengan kinerja bidan pada Kabupaten Gowa.

c. Hubungan Imbalan Dengan Kinerja Bidan

Tabel 6. Distribusi Kinerja Bidan Desa Menurut Imbalan di Kabupaten Gowa Tahun 2016

\begin{tabular}{|c|c|c|c|c|c|c|c|}
\hline \multirow{3}{*}{ Imbalan } & \multicolumn{4}{|c|}{ Kinerja Bidan } & \multirow{2}{*}{\multicolumn{2}{|c|}{ Total }} & \multirow{3}{*}{$\begin{array}{c}\text { Nilai P } \\
\text { (Chi square) }\end{array}$} \\
\hline & \multicolumn{2}{|c|}{ Kurang } & \multicolumn{2}{|c|}{ Baik } & & & \\
\hline & $\mathrm{N}$ & $\%$ & $\mathrm{n}$ & $\%$ & $\mathrm{n}$ & $\%$ & \\
\hline Kurang & 7 & 58,3 & 5 & 41,7 & 12 & 100 & \\
\hline Lebih & 9 & 29,0 & 22 & 71,0 & 31 & 100 & 0,035 \\
\hline Total & 16 & 37,2 & 27 & 62,8 & 43 & 100 & \\
\hline
\end{tabular}

Sumber : Data Primer, 2016

Tabel 6. Menunjukkan bahwa responden yang memiliki imbalan kurang kinerja kurang sebanyak 7 orang $(58,3 \%)$ kinerja baik sebanyak 5 (41,7\%), Sedangkan responden yang memiliki imbalan lebih kinerja kurang sebanyak 9 orang $(29,0 \%)$, kinerja baik 22 orang (71,0 $\%)$

Dari hasil uji chi square didapatkan hasil bahwa nilai p sebesar 0,035 . Hal ini berarti bahwa nilai $\mathrm{p}<$ dari 0,05 sehingga imbalan berhubungan dengan kinerja bidan pada Kabupaten Gowa. 


\section{Analisis Multivariat}

Untuk mengetahui hubungan beberapa variabel bebas yaitu Kemampuan, pengalaman, imbalan dengan kinerja bidan desa dilanjutkan dengan menggunakan analisis regresi logistik. Adapun hasil uji statistik multivariat dengan ujiregresi logistik dapat dilihat pada tabel berikut ini :

Tabel 7. Hasil Uji Statistik Regresi Logistik Variabel Kemampuan, Pengalaman, Imbalan Dengan Kinerja Bidan Di Kabupaten Gowa

\begin{tabular}{lccccccc}
\hline \multirow{2}{*}{ Variabel } & \multirow{2}{*}{ B } & \multirow{2}{*}{ S.E } & df & \multirow{2}{*}{ Sig. } & \multirow{2}{*}{ Exp (B) } & \multicolumn{2}{c}{ 95\% CI for Exp B } \\
\hline Kemampuan & 0,292 & 0,676 & 1 & 0,666 & 0,747 & 0,198 & 2,811 \\
\hline Pengalaman & 0,216 & 0,727 & 1 & 0,767 & 3,806 & 0,194 & 5,354 \\
\hline Imbalan & 1,321 & 0,741 & 1 & 0,075 & 0,075 & 0,062 & 1,142 \\
\hline
\end{tabular}

Sumber : Data Primer, 2016

Tabel 7. menunjukkan bahwa dengan analisis multivariat regresi logistic semua variabel bebas menunjukkan ada hubungan dengan kinerja bidan desa dalam pertolongan persalinan di Kabupaten Gowa, yang paling dominan adalah variabel pengalaman dengan nilai odds rasio atau $\operatorname{Exp}(B)=3,806$, dan nilai CL $95 \%$ Lower pada 0,194 dan Upper $=5,354$.

\section{PEMBAHASAN}

\section{Kinerja Bidan Desa dalam} Pertolongan Persalinan

Dari hasil penelitian tentang kinerja bidan desa di Kabupaten Gowa dapat diketahui bahwa kinerja responden yang termasuk kinerja kurang sebanyak 16 orang $(37,2 \%)$ dan responden yang memiliki kinerja baik sebanyak 27 orang $(62,8 \%)$. Keadaan tersebut sesuai dengan penelitian yang telah dilakukan oleh Darsiwan (2003), memberikan hasil bahwa dari jumlah 140 bidan desa di kabupaten Magelang memiliki tingkat kinerja yang cukup.

$$
\text { Akchadi (1996), telah }
$$
melakukan penelitian di 3 propinsi yaitu, Sulawesi Tenggara, Sulawesi Selatan dan Bengkulu, menyimpulkan bahwa ratarata jumlah persalinan yang di tolong oleh bidan desa selama tiga bulan berkisar sekitar $3-5$ persalinan. Sedangkan penelitian yang dilakukan oleh Widyawati (2003) tentang pemanfaatan pertolongan persalinan oleh tenaga kesehatan, mengatakan bahwa $85,6 \%$ ibu hamil sudah mengetahui fasilitas yang akan digunakan untuk pertolongan persalinannya. Namun ketersediaan fasilitas belum menjamin akan dimanfaatkan terutama bila tidak ada hubungan sosial yang baik antara bidan dan masyarakat. Masyarakat di Kabupaten Gowa terutama di pedesaan, masih lebih percaya kepada dukun beranak daripada kepada bidan apalagi dokter. Rasa takut masuk rumah sakit atau Puskesmas masih melekat pada kebanyakan kaum perempuan.

Kalaupun terjadi kematian ibu atau kematian bayi mereka terima sebagai musibah yang bukan ditentukan manusia. Selain itu masih banyak perempuan yang merasa malu melakukan pemeriksaan kandungan, apalagi persalinan oleh dokter atau para medis laki-laki.

Dengan sikap seperti itu, kebanyakan kaum perempuan di pedesaan tetap memilih dukun beranak sebagai penolong persalinan meskipun dengan resiko sangat tinggi. Dan keadaan ini sangat berpengaruh pada cakupan K1, $\mathrm{K} 4$, persalinan oleh tenaga kesehatan, Angka Kematian Ibu dan Angka Kematian Neonatus. Data yang didapatkan dari dinas kesehatan Kabupaten Gowa bahwa sampai dengan Desember tahun 2015 cakupan K1 sebesar 630 (61\%), K4 sebesar 311 (25\%), pertolongan persalinan oleh tenaga kesehatan sebesar $87 \%$, kematian ibu bersalin 10 kasus dan kematian neonatus sebesar 14 kasus.

\section{Hubungan Kemampuan dengan Kinerja Bidan Desa}

Hasil penelitian menunjukan ada kecenderungan bahwa responden yang mempunyai kemampuan kurang baik menghasilkan kinerja yang kurang baikpula, kecenderungan ini didukung oleh hasil analisis hubungan menggunakan uji chi square dengan perolehan nilai $\mathrm{p}$ sebesar $0,047(\mathrm{p}<0,05)$ 
yang artinya ada hubungan yang bermakna antara kemampuan dengan kinerja. Menurut pengelola KIA hal yang menyebabkan kemampuan bidan desa mempengaruhi kinerja kerja bidan desa di Kabupaten Gowa adalah Tingkat pendidikan bidan desa yang masih ada hanya D1, sehingga perlu ditingkatkan baik secara formal (jalur pendidikan) maupun non formal (pelatihan, kursus).

\section{Hubungan Pengalaman dengan Kinerja Bidan Desa}

Hasil uji Statistik dengan uji chi square menunjukkan bahwa pengalaman memiliki hubungan yang signifikan, yaitu nilai $\mathrm{p}$ sebesar 0,004. Hal tersebut berarti bahwa semakin tinggi pengalaman bidan desa, maka semakin meningkat kinerja kerja, khususnya didalam pertolongan persalinan.

\section{Hubungan Imbalan dengan Kinerja Bidan Desa}

Hasil penelitian dan uji statistik menunjukkan bahwa imbalan memiliki hubungan yang signifikan $(\mathrm{p}=0,035)$ pada kinerja bidan desa di Kabupaten Gowa. Berbeda dengan hasil penelitian ini didukung oleh penelitian yang dilakukan oleh Wawan Setiawan (2007) di kabupaten Tasik Malaya, bahwa imbalan tidak mempengaruhi kinerja bidan desa di kabupaten Tasik Malaya. Penelitian Widyawati (2003) menyatakan bahwa seluruh ibu bersalin yang ditolong oleh ibu bersalin mengeluarkan biaya persalinan,dan sebagian besar biaya persalinan oleh dukun lebih murah dibandingkan biaya persalinan oleh tenaga kesehatan. Notoatmodjo (1992) mengatakan tidak ada hubungan antara pendapatan bidan di desa dengan kinerja.

Imbalan memang perlu tapi di sisi lain tugas menolong persalinan (profesi) ini harus beroriantasi pada pengabdian. Tidak adanya hubungan antara imbalan dan kinerja bidan desa diasumsikan karena orientasi pengabdian dan imbalan tidak diukur dengan materi saja tetapi imbalan lain yang bisa didapatkan adalah bahwa setiap pertolongan persalinan merupakan salah satu kredit point bagi bidan desa untuk kenaikan pangkat dan golongan bidan.

\section{KESIMPULAN}

Berdasarkan hasil penelitian dapat diambil simpulan bahwa Kinerja bidan desa di Kabupaten Gowa dan hasil analisisnya dapat disimpulkan sebagai berikut :

1. Ada hubungan yang signifikan antara kemampuan dengan kinerja bidan desa di Kabupaten Gowa.

2. Ada hubungan yang signifikan antara pengalaman dengan kinerja bidan desa di Kabupaten Gowa.

3. Ada hubungan antara Imbalan dengan kinerja bidan desa di Kabupaten Gowa.

4. Pengalaman merupakan variabel yang paling berhubungan dengan kinerja bidan desa di Kabupaten Gowa.

Mengingat kinerja bidan desa ditentukan oleh faktor internal (kemampuan dan pengalaman) dan faktor eksternal (beban kerja), maka disarankan untuk meningkatkan kinerja bidan desa melalui:

1. Meningkatkan kemampuan dan pengalaman bidan melalui peningkatan pendidikan yang sesuai dengan standar, pelatihan, magang maupun simposium.

2. Memperhatikan beban kerja bidan desa agar tidak menghambat waktu bidan untuk menolong persalinan.

3. Hasil penelitian ini dijadikan sebagai bahan acuan dalam pengelolaan program KIA di Kabupaten Gowa.

\section{DAFTAR PUSTAKA}

Abdi, 2013. Analisis Efisiensi Alokasi Faktor-Faktor Produk Usahatani Jagung Manis Di Daerah Sabulakoa Kecamatan Landono Kabupaten Konawe Selatan. Majalah ilmiah agriplus volume 14 Nomor 01 Tahun 2013.

Achmad, 2012. Sistem Manajemen Kinerja. Jakarta, Gramedia Pustaka Utama.

Aditama tjandra yoga, 2012, Manajemen Administrasi Rumah Sakit, edisi kedua Universitas Indonesia Press, Jakarta

Alfikri, F, 2008, Pengaruh Motivasi Kerja, Kemampuan Kerja Dan Bimbingan Teknik Terhadap Kinerja Ajun Penyuluhan Keluarga Berencana Madya Di Daerah Khusus Ibukota Jakarta, tidak diterbitkan, Jakarta, 
Program Pascasarjana Universitas Indonesia.

Alam, S, 2009, Kinerja Bidan PNS Dan PTT Dalam Melaksanakan Kegiatan Antenatal Di Wilayah Lembah Palu Kabupaten Donggala, tidak diterbitkan, Yogyakarta, program pascasarjana universitas gajah mada.

Anastasi, A, 2008, Bidang-Bidang Psikologi Terapan, terjemahan oleh Aryatmi, dkk, 1989, Jakarta rajawali

Anderson, P, and Bill Wortman. The Quality Auditor Primer, edisi 3, quality council of Indiana.

Anoraga, pandji, 2008.Psikologi Kinerja, Jakarta, Rineka Cipta

Arep, ishak \& hendri tanjung, 2013.Manajemen Motivasi. Jakarta : Grasindo

Arikunto, suharsimi, 2012. Manajemen Penelitian. Jakarta : rineka cipta

As'ad, m, m, 2008, Psikologi Industry: Yogyakarta, edisi keempat, cetakan pertama, liberti.

Basjuni, I, f, 2001, Analisis Kinerja Pelaksana Perkesmas Terhadap Cakupan Penemuan Penderita Baru Tbc (Bta+) Di Puskesmas Kabupaten Musi Banyuasin, tidak diterbitkan, Jakarta, program pascasarjana universitas Indonesia

Biro pusat statistic, 2013.Kabupaten Gowa Dalam Angka 2013. Bps Kabupaten Gowa.

Depkes RI, 2012. Profil kesehatan Indonesia tahun 2012. Jakarta : Depkes

Dessler, G, 2012, Manajemen Sumber Daya Manusia, terjemahan oleh Benyamin Molan, 1997, Jakarta, PT.Prenhallindo

Departemen Kesehatan RI, 2012, Panduan Bidan Di Tingkat Daerah, Jakarta Depkes RI
Departemen Kesehatan RI, 2012, Pedoman Pelayanan Antenatal Di Tingkat Pelayanan Dasar, Jakarta Depkes RI

Dinas Kesehatan Kabupaten Gowa, 2013, Profil Kesehatan Kabupaten Gowa 2013, Sulawesi Selatan.

Furtwengler, dale, 2012.Penilaian Kinerja. Yogyakarta, Penerbit Andi Offset

Gibson, Ivancevich, dan Donelly, 2010, Fundamental of management, terjemahan, edisi kesembilan, Jakarta, erlangga

Green, LW et. Al, 2010. Perencanaan Pendidikan Kesehatan, Sebuah Pendekatan Diagnostic; terjemahan dari zarfiltafal, zulasmi mamdy dan suarti kresno, proyek pengembangan Fakultas Kesehatan Masyarakat, Jakarta Depdibub RI

Guilbert, JJ, 2012, Education Handbook For Health Personal, WHO, terjemahan WF. Maramis

Hamzah, 2011, Faktor-Faktor Yang Berhubungan Dengan Prestasi Kerja Bidan, Kabupaten Subang Provinsi Jawa Barat.Program Pascasarjana Universitas Indonesia Program Studi Kajian Administrasi Rumah Sakit.

HMHB, 2013.Laporan Akhir Proyek Healthy Mothers Healthy Babies(HMHB). : HMHB (tidak dipublikasikan)

Ilyas, Y, 2008, Kinerja, Teori, Penilaian Dan Penelitian Depok, badan penerbit FKM UI.

Kopelman, Richard E, 2009. Managing Productivity In Organitazion A Practical, People Oriented Perspective, New York : Mc. Graw Hill

Krowinski,JW and Steiber, SR, 2011, Measuring And Patient Satisfaciont. 2nd ed, American hospital association company

Locke, KA, 2011, what job satisfaction? Organitation behavior and human 
performance, 4ed, new York, prentice Hill.

Maxwell, J, C, 2005 Mengembangkan Kepemimpinan Di Dalam Diri Anda, terjemahan oleh anton adiwiyoto, 1995, Jakarta, binarupa aksara

Mulyono, mauled, SE, 2012. Penerapan Produktivitas Dalam Organisasi. Jakarta, bumi aksara

Murti, B, 2011, Penerapan Metode Statistic Non Parametric Dalam Ilmu-Ilmu Kesehatan. Jakarta, PT. gramedia pustaka utama

Notoatmodjo, 2012. Pengembangan Sumber Daya Manusia, cetakan pertama, Jakarta aneka cipta

Notoatmodjo S, 2012, Metodelogi Penelitian Kesehatan, cetakan kedua, PT. Jakarta, Rineka cipta

Porter, LW, 2011. A Study Of Perceived Need Satisfaction Botton And Middle Management Job, dalam DE porter da PB Applewwhite(eds); study in organitazional behavior management, international textbook company, new York

Prawirosentono, suyadi, 2008. Kebijakan Kinerja Karyawan. Yogyakarta, BPFE.

Rajab LB, 2013. Studi Kualitas Kinerja Bidan di Kabupaten Gowa. Pascasarjana Universitas Hasanuddin Program Studi Adminsitrasi Pembangunan.

Riyadi, Slamet, 2012. Ilmu Kesehatan Masyarakat. Surabaya: Usaha Nasional.

Robins, Stephen P. 2011. Perilaku Organisasi: Konsep, Kontroversi, Aplikasi. Jakarta:Prenhalindo.

Santoso, S, 2000, Buku Latihan SPSS Statistik Parametrik, Jakarta, Elex Media Komputindo.
Sastrowiharjo, Siswanto, 2012. Manajemen Tenaga Kerja Indonesia.Pendekatan Administratif dan Operasional.Jakarta : Bumi Aksara

Siagian, Jones, 2009, Staff Satisfaction About Sangau Hospital's Organization Climate The University of NewCastle.

Siagian, Sondang, Prof.Dr, MPA, Kiat Meningkatkan Produktivitas Kerja. Jakarta, Rineka Cipta

Simajuntak, Payaman, 2005. Pengantar Ekonomi Sumberdaya Manusia. Jakarta, LPFE-UI.

Sinungan, Muchdarsyah, 2013. Produktivitas Apa Dan Bagaimana. Jakarta, Bumi Aksara

Sugiyono. 2012. Statistika Untuk Penelitian. Bandung: Alfabeta

Stoner,JAF, 2012, Management, terjemahan, Jakarta, Erlangga.

Sugandi, S, 2012, Faktor-Faktor Yang Berhubungan Dengan Kinerja Bidan di Kabupaten Tasikmalaya Jawa Barat, Jakarta.Program Pascasarjana Universitas Indonesia. 